${ }^{9}$ Dresser DW, Gowland G. Immunological paralysis induced in adult rabbits by small amounts of a protein antigen. Nature 1964;203:733-6.

${ }^{10}$ Hellström KE, Hellström I. Lymphocyte-mediated cytotoxicity and blocking serum activity to tumor antigens. Adv Immunol 1974 ;18:209-77.

11 Stevenson FK, Hamblin TJ, Stevenson GT, Tutt AL. Extracellular idiotypic immunoglobulin arising from human leukemic B lymphocytes. f Exp Med 1980;152:1484-96.

12 Greaves M, Delia D, Janossy G, et al. Acute lymphoblastic leukaemia associated antigen. IV. Expression on non-leukaemic 'lymphoid' cells. Leuk Res 1980;4:15-32.

${ }^{13}$ Metzgar RS, Borowitz MJ, Jones NH, Dowell BL. Distribution of common acute lymphoblastic leukemia antigen in nonhematopoietic tissues. f Exp Med 1981;154:1249-54.

14 Stevenson GT, Elliott EV, Stevenson FK. Idiotypic determinants on the surface immunoglobulin of neoplastic lymphocytes: a therapeutic target. Fed Proc 1977;36:2268-71.

${ }^{15}$ Hatzubii A, Maloney DG, Levy R. The use of a monoclonal anti-idiotype antibody to study the biology of a human B cell lymphoma. F Immunol $1981 ; 126: 2397-402$.

${ }^{16}$ Hough DW, Eady RP, Hamblin TJ, Stevenson FK, Stevenson GT. Antiidiotype sera raised against surface immunoglobulin of human neoplastic lymphocytes. F Exp Med 1976;144:960-9.

17 Krolick KA, Uhr JW, Vitetta ES. Selective killing of leukaemia cells by antibody-toxin conjugates: implications for autologous bone marrow transplantation. Nature $1982 ; 295: 604-5$.

18 Boyse EA, Old LJ. Some aspects of normal and abnormal cell surface genetics. Annu Rev Genet 1969;3:269-90.

19 Gordon J, Stevenson GT. Antigenic modulation and lymphocytic surface immunoglobulin yielding resistant to complement-mediated lysis. II. Relationship to redistribution of the antigen. Immunology 1981;42:13-7.

${ }^{20}$ Nord S, Weissman IL. Radiolabelled antitumor antibodies. III. Highly iodinated and highly radio-iodinated antibodies. $7 N C I$ 1974;53:959-65.

21 Ghose T, Norvell ST, Guclu A, Cameron D, Bodurtha A, MacDonald AS. Immunochemotherapy of cancer with chlorambucil-carrying antibody. Br Med f 1972 ;iii:495-9.

${ }^{22}$ Rubens RD, Dulbecco R. The augmentation of cytotoxic drug action by antibodies directed at cell surface. Nature 1974;248:81-2.

${ }^{23}$ Moolten FL, Capparell NJ, Zajdel SH, Cooperband SR. Antitumor effects of antibody-diphtheria toxin conjugates. II. Immunotherapy with conjugates directed against tumor antigens induced by simian virus 40. FNCI $1975 ; 55: 473-7$.

24 Glennie MJ, Stevenson GT. Univalent antibodies kill tumour cells in-vitro and in-vivo. Nature $1982 ; 295: 712-3,4$.

\section{Neuroleptics and abnormal movements}

As soon as drugs such as chlorpromazine and haloperidol came into clinical use they were found to have considerable effects on involuntary movements. The neurological syndromes associated with antipsychotics or neuroleptic drugs are acute dystonias, akathisia, Parkinsonism, and akinetic mutism-all reversible if treatment is stopped-and tardive dyskinesia, which in some cases may persist.

On the other hand, neuroleptic drugs have also proved useful in the management of spontaneously occurring movement disorders. For example, Huntington's disease is characterised by chorea, mental deterioration, and behavioural changes. The patient is clumsy, restless, and fidgety, and in the later stages the dementia becomes more profound and the chorea more grotesque, all parts of the body writhing, twisting, and turning in incessant uncontrollable movements. In the past, reserpine, which depletes nerve endings of dopamine, was used in treatment, but now neuroleptics are generally used. ${ }^{1}$ Fahn $^{2}$ reported that the chorea was helped by perphenazine, and Whittier and Korenyi ${ }^{3}$ found that 43 of 65 patients with Huntington's chorea improved with fluphenazine.

Neuroleptics have been more systematically evaluated in Gilles de la Tourette's syndrome. This rare, strange condition develops in childhood or early adolescence and has a prolonged course, with motor tics affecting the head and body together with verbal ejaculations-grunts, sounds, words, or phrases that may be obscene. Treatment with neuroleptics is the only drug regimen that consistently ameliorates the symptoms. ${ }^{4}$ In a controlled study, $6 \mathrm{mg}$ diazepam a day was no better than placebo in treating four patients, but haloperidol was appreciably superior. ${ }^{5}$ Bruun and her co-workers ${ }^{6}$ treated 59 patients, finding that an average dose of $13 \mathrm{mg}$ haloperidol a day improved symptoms by $80 \%$. The dose required is extremely variable and treatment should include continuous monitoring. As the duration of treatment increases the effectiveness of haloperidol seems to improve, so that some diminution in dosage may be possible in time. Dosage may need to be increased during exacerbations. Akinesia, sometimes misinterpreted as clinical depression, is the commonest unwanted effect and is especially apparent in patients having doses above $5 \mathrm{mg}$ haloperidol a day. Phenothiazines seem consistently less effective than haloperidol, though no controlled comparisons have been published. Some patients have responded only marginally to high doses of phenothiazines but remitted almost completely with low doses of haloperidol.

Stuttering is another motor disorder for which haloperidol has been found useful. In one study the drug diminished the amount of time the eight patients were dysfluent but not the number of dysfluencies a minute. ${ }^{7}$ The hesitation and phonemic stoppage of the severe stutterer may be helped, and the facial contortions accompanying stuttering may almost completely disappear. Low dosages (about $3 \mathrm{mg}$ haloperidol a day in divided doses) are recommended, but even so some young patients find the extrapyramidal side effects intolerable.

Intractable hiccups have long been known to respond to neuroleptics. The early observations related to chlorpromazine, and there are no controlled data concerning haloperidol, which, to extrapolate from the responsiveness of patients with Tourette's syndrome, might be more effective. Another repetitive paroxysm is uncontrollable sneezing. Davison ${ }^{8}$ has described a 60 -year-old woman referred for psychiatric advice for severe, intractable sneezing. On the reasonable hypothesis that repetitive sneezing might be related to other forms of repetitive involuntary movements oral haloperidol was prescribed, with complete remission.

Does the response of repetitive abnormal motor conditions to haloperidol and other neuroleptics tell us anything about the pathogenesis of these curious conditions? Neuroleptics block dopamine receptors, varying among themselves with respect to their potency on receptors in various parts of the brain. Cholinergic pathways and gamma-aminobutyric acid seem abnormal in patients with Huntington's chorea, ${ }^{9}$ and perhaps 5-hydroxytryptamine in Tourette's syndrome ${ }^{1011}$ but it would be premature to conclude that dopaminergic neurones are implicated in the pathogenesis of all the movement disorders described above. The long-term effects of haloperidol differ from its acute effects-for example, the turnover of acetylcholine in the rat striatum reverts to normal with repeated administration of haloperidol. ${ }^{12}$ The only common factor in all these conditions may be that the abnormal movements are mediated via a final common pathway under dopaminergic control.

M H LADER

Professor of Clinical Psychopharmacology,

Institute of Psychiatry,

London SE5 6AF

1 Chase TN. National approaches to the pharmacotherapy of chorea In: Yahr MD, ed. Basal ganglia. New York: Raven Press, 1976:337-50. (Association for Research in Nervous and Mental Disease (ARNMD), Research Publications, vol 55.)

2 Fahn S. Perphenazine in Huntington's chorea. Adv Neurol 1973;1:755-64.

3 Whittier JR, Korenyi C. Effect of oral fluphenazine on Huntington's chorea. International fournal of Neuropsychiatry 1968;4:1-3. 
4 Woodrow KM. Gilles de la Tourette's disease-a review. Am $\mathcal{F}$ Psychiatry 1974;131:1000-3.

5 Connell PH, Corbett JA, Horne DJ, Mathews AM. Drug treatment of adolescent tiqueurs. A double-blind trial of diazepam and haloperidol. Br F Psychiatry 1967;113:375-81.

${ }^{6}$ Bruun RD, Shapiro AK, Shapiro E, Sweet R, Wayne H, Solomon GE. A follow-up of 78 patients with Gilles de la Tourette's syndrome. Am $\mathcal{F}$ Psychiatry 1976;133:944-7.

${ }^{7}$ Rosenberger PB, Wheelden JA, Kaltokin M. The effect of haloperidol on stuttering. Am $\mathcal{f}$ Psychiatry 1976;133:331-4.

${ }^{8}$ Davison K. Pharmacological treatment or intractable sneezing. $\mathrm{Br} \mathrm{Medf}$ $1982 ; 284: 1163-40$

${ }^{9}$ Aquilonius S-M, Eckernäs S- $\AA$, Sundwall A. Regional distribution of choline acetyltransferase in the human brain: changes in Huntington's chorea. F Neurol Neurosurg Psychiatry 1975;38:669-77.

${ }^{10}$ Cohen DJ, Shaywitz BA, Joung JG, et al. Central biogenic amine metabolism in children with the syndrome of chronic multiple tics of Gilles de la Tourette: norepinephrine, serotonin, and dopamine. f Am Acad Child Psychiatry 1979;18:320-41.

11 Van Woert MH, Jutkowitz R, Rosenbaum D, Bowers MB. Gilles de la Tourette's syndrome: biochemical approaches. In: Yahr MD, ed. Basal ganglia. New York: Raven Press, 1976:459-65. (Association for Research in Nervous and Mental Disease (ARNMD), Research Publications, vol 55.)

12 Mao CC, Cheney DL, Marco E, Revuelta A, Costa E. Turnover times of gamma-aminobutyric acid and acetylcholine in nucleus caudatus, nucleus accumbens, globus pallidus and substantia nigra: effects of repeated administration of haloperidol. Brain Res 1977;132:375-9.

\section{Pregnancy in the Marfan syndrome}

The Marfan syndrome, an inherited disorder of connective tissue, has a wide geographic and ethnic distribution. The primary features are arachnodactyly, a characteristic habitus because of excessive length of the limbs, and dislocation of the lens. Cardiovascular complications frequently occur, and a substantial proportion of affected people die from aortic incompetence or dissection secondary to progressive changes in the root of the aorta, ${ }^{1}$ the average age of death in a series of 72 patients with the syndrome being $32 .^{2}$

A minimum prevalence of about 1.5 per 100000 has been calculated for Northern Ireland, ${ }^{3}$ and if this figure is valid for other populations there will be at least 750 people with the condition in Britain and around 4000 in the United States.

What advice can be given to a young woman with the Marfan syndrome who is contemplating pregnancy? Can an objective appraisal be made of the risks to the mother and fetus ? Lethal or life-threatening aortic dissection has been reported during pregnancy on several occasions, ${ }^{4-6}$ but these patients may have represented extreme examples; many others are known to have had uneventful pregnancies. Pyeritz has recently reviewed the pregnancies of 26 affected women, ${ }^{7}$ using wives of men with the Marfan syndrome and mothers of sporadic "new mutant" children as controls. He found no differences in the incidence of general complications of pregnancy in these groups, though the spontaneous abortion rate was higher in the women with the Marfan syndrome. Only one of the 26 affected women had evidence of any serious cardiovascular disorder before pregnancy, and she died in the puerperium from endocarditis.

Pyeritz concluded that the risk of death in pregnancy is low in women with the Marfan syndrome who have minimal cardiovascular disease. In contrast, published reports strongly suggest that those with aortic or mitral valvular disease or dilatation of the aortic root are at high risk of potentially lethal complications in pregnancy or during the postnatal period. Pyeritz recommended that a minimum aortic diameter of more than $40 \mathrm{~mm}$, as measured by echocardiographic techniques, or any cardiac decompensation should be taken as contraindications to pregnancy. Conversely, affected women who lack these changes might be advised to proceed with pregnancy under strict obstetric and medical supervision -and they might be urged to complete reproduction early in life before the onset of cardiovascular problems.

The Marfan syndrome is transmitted as an autosomal dominant trait, so any offspring of an affected parent will have an even chance of inheriting the faulty gene and manifesting the disorder. The features in the fetus and newborn are minor, and a child with the condition does not seem to pose any threat to the mother, or vice versa, during pregnancy.

Whether the recognition of the Marfan syndrome in a fetus would justify therapeutic termination of pregnancy is debatable, but prenatal diagnosis by ultrasonography has been attempted in two "at-risk" pregnancies in the second trimester. ${ }^{8}$ In one instance the Marfan syndrome was diagnosed by finding excessive length of the fetal limbs, and after termination typical histological changes were seen in the aorta. In the other pregnancy fetal limb length, as determined by ultrasonography, did not differ from normal, and the pregnancy continued to term. By the age of 21 months some disparity was evident, and the child was thought probably to be affected. On this basis it is evident that, though there is a place for antenatal ultrasonography, definitive diagnosis is not always possible.

Unfortunately diagnosis of the Marfan syndrome may be difficult-both in the adult and in the fetus. In clinical practice several minor examples or formes frustes are encountered for every patient with the full-blown syndrome, and it is often very difficult to know where normality ends and a syndrome begins. To paraphrase McKusick, the greatest problem in the Marfan syndrome is the diagnosis of the disorder in the first place.

Peter Beighton

Professor of Human Genetics,

University of Cape Town Medical School,

Observatory 7925 ,

South Africa

1 Pyeritz RE. Diagnosis and management of cardiovascular disorders in the Marfan syndrome. Fournal of Cardiovascular Medicine 1980;5:759-69.

${ }^{2}$ Murdoch JL, Walker BA, Halpern BL, Kuzma JW, McKusick VA. Life expectancy and causes of death in the Marfan syndrome. N Engl $\mathcal{F}$ Med $1972 ; 286: 804-8$.

3 Lynas MA. Marfan's syndrome in Northern Ireland: an account of thirteen families. Ann Hum Genet 1958;22:289-309.

4 Cava EF, Dreier RL. The Marfan syndrome in pregnancy: a case report. Am F Obstet Gynecol 1971;110:250-4.

5 Elias S, Berkowitz RL. The Marfan syndrome and pregnancy. Obstet Gynecol 1976;47:358-61.

- Rivlin ME. Marfan's syndrome and pregnancy. Fournal of Obstetrics and Gynaecology of the British Commonwealth 1967;74:143-4.

7 Pyeritz RE. Maternal and fetal complications of pregnancy in the Marfan syndrome. $A m \mathcal{F}$ Med $1981 ; 71: 784-90$.

8 Koenigsberg M, Factor S, Cho S, Herskowitz A, Nitoswky H, Morechi R. Fetal Marfan syndrome. Prenatal ultrasound diagnosis with pathological confirmation of skeletal and aortic lesions. Prenatal Diagnosis $1981 ; 1: 241-7$. 